Research Paper

\title{
Surgical Treatment of Combined Hepatocellular- Cholangiocarcinoma is as Effective in Elderly Patients as it is in Younger Patients: A Propensity Score Matching Analysis
}

Chen-Yang Tao ${ }^{*}$, Wei-Ren Liu ${ }^{*}$, Lei Jin ${ }^{1}$, Zheng Tang1, Meng-Xin Tian ${ }^{1}$, Xi-Fei Jiang1, Han Wang1, Pei-Yun

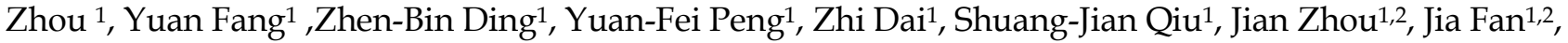
and Ying-Hong Shi ${ }^{1 \times}$

1. Department of Liver Surgery, Liver Cancer Institute, Zhongshan Hospital, Fudan University; Key Laboratory of Carcinogenesis and Cancer Invasion of Ministry of Education, Shanghai, China.

2. Institutes of Biomedical Sciences, Fudan University, Shanghai, People's Republic of China.

* These authors contributed equally to this work

$\triangle$ Corresponding author: Dr. Ying-Hong Shi, Address: Department of Liver Surgery, Liver Cancer Institute, Zhongshan Hospital, Fudan University, 180 FengLin Road, Shanghai, 200032, China. Tel.: (+86)-21-64041990-608621; fax: (+86)-21-64037181; E-mail: shi.yinghong@zs-hospital.sh.cn

(c) Ivyspring International Publisher. This is an open access article distributed under the terms of the Creative Commons Attribution (CC BY-NC) license (https://creativecommons.org/licenses/by-nc/4.0/). See http://ivyspring.com/terms for full terms and conditions.

Received: 2017.11.19; Accepted: 2018.01.28; Published: 2018.02.28

\begin{abstract}
Aims: To compare the long-term prognosis of younger and elderly patients with combined hepatocellular-cholangiocarcinoma (CHC) who underwent curative resection between 1993 and 2014 at our center.

Methods: Two hundred and thirteen patients who underwent liver resection for $\mathrm{CHC}$ were enrolled in our study. The overall survival (OS) and disease-free survival (DFS) of elderly patients (age $\geq 60, n=52$ ) and younger patients (age $<60, n=161$ ) were compared by multivariate analysis and propensity score matching (PSM) analysis.

Results: Among the $213 \mathrm{CHC}$ patients, the elderly patients had a higher rate of worse Child-Pugh grade $(P=0.027)$, abnormal serum albumin $(P<0.001)$ and lymphoid metastases $(P=0.024)$. The proportion of HBV-positive CHC patients $(74.6 \%, 159 / 213)$ was much higher than that observed in healthy cohorts. Younger patients had a higher rate of hepatitis B virus (HBV) infection compared to older patients $(83.9 \%$ vs $46.2 \%, \mathrm{P}<0.001)$. OS and DFS of the elderly and younger patients before and after propensity score matching were comparable.

Conclusion: Elderly and younger patients who underwent liver resection for $\mathrm{CHC}$ have comparable long-term OS and DFS.
\end{abstract}

Key words: Combined Hepatocellular-Cholangiocarcinoma, Hepatic resection, age, Propensity score matching

\section{Introduction}

Hepatocellular carcinoma (HCC) and intrahepatic cholangiocarcinoma (ICC) constitute the most common primary liver malignancies ${ }^{[1]}$. $\mathrm{CHC}$ is a rare type of primary liver cancer that shares the histopathologic characteristics of both cholangiocarcinoma (CC) and $\mathrm{HCC}^{[2]}$. According to the latest WHO classification of the digestive system, $\mathrm{CHC}$ is divided into two histological types: a classical type and subtypes with stem cell features ${ }^{[3]}$.

The imaging characteristics of HCC and ICC have been widely investigated by contrast-enhanced MRI or CT. CHC may share typical features with HCC and ICC, such as arterial enhancement and portal washout, whereas the remaining tumor regions may 
show a delayed enhancement and biliary ductal dilation[2, 4]. Taken together, the preoperative diagnosis of $\mathrm{CHC}$ remains a challenge. Some clinicians suggest that the discordance between imaging features and the elevation of tumor marker levels could indicate $\mathrm{CHC}[2,4,5]$.

Due to the low prevalence of $\mathrm{CHC}$, the clinical characteristics of this disease are poorly understood. Some studies indicated that $\mathrm{CHC}$ may show clinical characteristics resembling HCC, but the OS was more similar to that of ICC[6]. Surgical resection remains the treatment of choice for CHC patients and yields better survival benefits than other treatment options $[1,6,7]$.

In retrospective studies, the propensity score analysis has been widely used to reveal the true treatment effect by balancing the confounders between younger patients and elderly patients[8-10]. Several studies have demonstrated by PSM analysis that HCC and ICC have comparable long-term OS and DFS in younger and elder [11-15]. However, to date, no study has evaluated the effect of age after hepatectomy in $\mathrm{CHC}$ patients. In the present study, the prognostic factors that influence OS and DFS was analyzed. Thereby, PSM analysis was adopted to remove bias caused by these factors in order to reveal the true effect of age.

\section{Patients and Methods}

\section{Study Population and Data Collection}

Between March 1993 and December 2014, 269 patients diagnosed with pathologically confirmed $\mathrm{CHC}$ were recruited at the Department of Liver Surgery, Zhongshan Hospital. Surgical techniques for liver resection were described elsewhere[16], and the pathology of $\mathrm{CHC}$ was diagnosed according to World Health Organization criteria[3]. Preoperative imaging examinations including chest $X$-ray, abdominal ultrasonography, contrast-enhanced computer tomography (CT) or magnetic resonance imaging (MRI), were performed routinely. Serum biochemical and prothrombin time data and the presence of ascites were used to assess liver function. Patients with Child A cirrhosis, and early Child B cirrhosis were considered for resection: the former were offered resections up to $50 \%$, while the latter were offered up to $25 \%$ [17]. Eight patients were excluded for other therapeutic modalities, 11 patients were excluded due to missing data, 25 patients were excluded for preoperative therapy, four patients were excluded due to recurrence within one month after surgery, and eight patients dropped out of the study. Overall, 213 patients were included in the study. The patients were categorized into two groups, the "younger" group (age $<60, \mathrm{n}=161$ ) and the "elderly" group (age $\geq 60$, $\mathrm{n}=52$ ). The study was approved by the Institutional Review Board of the Zhongshan Hospital and complied with the standards of the Declaration of Helsinki and current ethical guidelines.

\section{Follow up}

Patients were followed up every 3 months until death or dropping out of the follow-up program. Abdominal ultrasound, liver function tests, serum alpha-fetoprotein (AFP) levels, carcinoembryonic antigen (CEA) levels and carbohydrate antigen 19-9 (CA19-9) levels were analyzed every 3 months, and abdominal magnetic resonance imaging (MRI) was performed every 6 months. The end-point of the study was overall survival (OS), which was defined as the interval between the date of surgery and the date of the patient's death or final follow-up.

The diagnosis of recurrence was based on MRI imaging findings, increased serum AFP and CA19-9 levels. Extrahepatic recurrence was also examined by chest $\mathrm{CT}$ and bone scintigram. Based on the recurrence pattern and the liver function reserve, the patients were managed with different therapeutic modalities, including radiofrequency ablation (RFA), repeated resection for resectable recurrence, TACE, percutaneous ethanol injection (PEI), and chemotherapy for patients with extrahepatic metastatic disease.

\section{Statistical Analysis}

Demographic, clinical and tumor characteristics are described as summary statistics, which were obtained using established methods. In both younger and elderly cohorts, continuous data were presented as the mean and the 25th-75th percentile range and analyzed using the Mann-Whitney $U$ test. The categorical variables were described as absolute and relative frequencies and compared using Pearson $x^{2}$ analysis or the Fisher exact test. OS and DFS were compared using the Kaplan-Meier method, and the survival differences between the two groups were compared using the log-rank test.

Logistic regression was used for the propensity score matching analysis to estimate the propensity score (from 0 to 1 ), which contains information on the variates selected. To create a reliable propensity score model, the variables chosen for matching should include all the potential confounders. ${ }^{[8-10]}$ Instead, the variables should contain all the independent prognostic factors of $\mathrm{CHC}$. The Cox proportional hazards model was used to identify the independent prognostic factors. Then, the statistically significant variables $(\mathrm{P}<0.1)$ obtained from the univariate analysis were used in the multivariate analysis. The variables entered in the final propensity model were 
gender, the serum level of carcinoembryonic antigen, y-glutamyl transpeptidase (GGT), macroscopic vascular invasion (MVI), portal lymph node invasion and extrahepatic metastases. The model used the one-toone match without replacement between younger and elderly patients using the nearest-neighbor matching algorithm. The caliper value was set to 0.01 , and the balance between the two groups after matching was evaluated by the standardized mean difference $(<0.1)$.

All tests using a two-tailed $P$-value $<0.05$ were considered to be statistically significant. All statistical analyses were performed using the SPSS 22.0 statistical package (SPSS Incorporated, Chicago, Illinois, USA) and the design and survival packages. This project was approved by our institutional review board.

\section{Results}

\section{Demographic and Clinicopathological Characteristics}

The demographic and clinicopathological characteristics are shown in Table 1. The mean age of the entire cohort was 52.4 years. One quarter of the patients were $\geq 60$ years old $(n=52,24.3 \%)$, whereas the remaining patients were $<60$ years old $(n=161,75.7 \%)$. A higher proportion of the younger patients had HBV infection $(\mathrm{P}<0.001)$. In contrast, the elderly patients had a poor liver function $(\mathrm{P}=0.027)$, a high occurrence of abnormal serum albumin $(\mathrm{P}<0.001)$ and the presence of ascites $(\mathrm{P}=0.011)$. For the tumor characteristics, the elderly patients showed a high occurrence of portal lymph node invasion $(\mathrm{P}=0.024)$.

\section{The prognostic factors of combined hepatocellular carcinoma-cholangiocarcinoma}

To identify the potential confounders, the Cox proportional hazards model was used to analyze the risk factors of $\mathrm{CHC}$ (Table 2). With regard to OS, the following 12 variates determined by the univariate analysis were included in the multivariate analysis: gender (male), the Child-Pugh grade, CEA, CA19-9, albumin, GGT, tumor number, tumor size, MVI, portal lymph node invasion, and extrahepatic metastases. The multivariate analysis revealed that CEA, GGT, MVI, lymphoid metastases, and extrahepatic metastases were independent prognostic factors of OS. For DFS, the following 4 variates determined by univariate analysis were included in the multivariate analysis: gender, GGT, MVI and portal lymph node invasion. The multivariate analysis indicated that gender, MVI, and portal lymph node invasion were independent risk factors for predicting a poor DFS. Age was not an independent factor for OS $(\mathrm{P}=0.190)$ or DFS $(\mathrm{P}=0.292)$ in either the univariate or multivariate analyses.
Table 1. Comparison of Demographic Data and Outcomes Between Younger ( $\leqslant 60$ Years of Age) and Elderly ( $>60$ Years of Age) Patients With $\mathrm{CHC}$

\begin{tabular}{|c|c|c|c|c|}
\hline & $\begin{array}{l}\text { Total } \\
(n=213)\end{array}$ & $\begin{array}{l}\text { Younger } \\
\text { patients } \\
(n=161)\end{array}$ & $\begin{array}{l}\text { Elderly } \\
\text { patients } \\
(n=52)\end{array}$ & $\begin{array}{l}P \\
\text { value }\end{array}$ \\
\hline Age (yrs.) & $52.4 \pm 8.7$ & $47.4 \pm 8.7$ & $67.7 \pm 4.9$ & $<0.001$ \\
\hline Gender: Male & $161(75.6 \%)$ & $123(76.4 \%)$ & $38(73.1 \%)$ & 0.682 \\
\hline HBV: Positive & $159(74.6 \%)$ & $135(83.9 \%)$ & $24(46.2 \%)$ & $<0.001$ \\
\hline HCV: Positive & $5(2.3 \%)$ & $3(1.9 \%)$ & $2(3.8 \%)$ & 0.597 \\
\hline \multicolumn{5}{|l|}{ Child-Pugh Class } \\
\hline A & $202(94.8 \%)$ & $156(96.9 \%)$ & $46(88.5 \%)$ & \multirow[t]{2}{*}{0.027} \\
\hline B & $11(5.2 \%)$ & $5(3.1 \%)$ & $6(11.5 \%)$ & \\
\hline \multicolumn{5}{|l|}{$\operatorname{AFP}(\mathrm{ng} / \mathrm{ml})$} \\
\hline$\leq 20$ & $99(46.5 \%)$ & $76(47.2 \%)$ & $23(44.2 \%)$ & \multirow[t]{2}{*}{0.622} \\
\hline$>20$ & $114(53.5 \%)$ & $85(52.8 \%)$ & $29(55.8 \%)$ & \\
\hline \multicolumn{5}{|l|}{ CEA (ng/ml) } \\
\hline$\leq 5$ & $174(81.7 \%)$ & $132(82 \%)$ & $42(80.8 \%)$ & \multirow[t]{2}{*}{0.911} \\
\hline$>5$ & $39(18.3 \%)$ & $29(18 \%)$ & $10(19.2 \%)$ & \\
\hline \multicolumn{5}{|l|}{ CA199 (U/ml) } \\
\hline$\leq 37$ & $140(65.7 \%)$ & $106(65.8 \%)$ & $34(65.4 \%)$ & \multirow[t]{2}{*}{0.862} \\
\hline$>37$ & $73(34.3 \%)$ & $55(34.2 \%)$ & $18(34.6 \%)$ & \\
\hline $\mathrm{TB}(\mu \mathrm{mol} / \mathrm{L}):>17$ & $41(18.8 \%)$ & $29(17.6 \%)$ & $12(22.6 \%)$ & 0.674 \\
\hline $\operatorname{ALB}(g / L):<40$ & $73(33.5 \%)$ & $45(27.3 \%)$ & $28(52.8 \%)$ & 0.001 \\
\hline $\operatorname{ALT}(\mathrm{U} / \mathrm{L}):>35$ & $90(41.3 \%)$ & $72(43.6 \%)$ & $18(34 \%)$ & 0.213 \\
\hline GGT (U/L): >40 & $155(71.1 \%)$ & $114(69.1 \%)$ & $41(77.4 \%)$ & 0.248 \\
\hline \multicolumn{5}{|l|}{ Ascites (ml) } \\
\hline No & $193(90.6 \%)$ & $151(93.8 \%)$ & $42(80.8 \%)$ & \multirow[t]{2}{*}{0.011} \\
\hline Yes & $20(9.4 \%)$ & $10(6.2 \%)$ & $10(19.2 \%)$ & \\
\hline \multicolumn{5}{|l|}{ Tumor nodularity } \\
\hline Single & $159(74.6 \%)$ & $118(73.3 \%)$ & $41(78.8 \%)$ & \multirow[t]{2}{*}{0.423} \\
\hline Multiple & $54(25.4 \%)$ & $43(26.7 \%)$ & $11(21.2 \%)$ & \\
\hline Tumor Diameter $(\mathrm{cm})$ & $6.4(3.5-8.0)$ & $6.4(3.5-8.0)$ & $6.4(3.3-7.7)$ & 0.852 \\
\hline \multicolumn{5}{|l|}{ Macroscopic VI } \\
\hline No & $200(93.9 \%)$ & $151(93.8 \%)$ & $49(94.2 \%)$ & \multirow[t]{2}{*}{1.000} \\
\hline Yes & $13(6.1 \%)$ & $10(6.2 \%)$ & $3(5.8 \%)$ & \\
\hline \multicolumn{5}{|l|}{ Microscopic VI } \\
\hline No & $167(78.4 \%)$ & $124(77 \%)$ & $43(82.7 \%)$ & \multirow[t]{2}{*}{0.309} \\
\hline Yes & $46(21.6 \%)$ & $37(23 \%)$ & $9(17.3 \%)$ & \\
\hline \multicolumn{5}{|l|}{ Lymphoid Metastases } \\
\hline No & $188(88.3 \%)$ & $147(91.3 \%)$ & $41(78.8 \%)$ & \multirow[t]{2}{*}{0.024} \\
\hline Yes & $25(11.7 \%)$ & $14(8.7 \%)$ & $11(21.2 \%)$ & \\
\hline \multicolumn{5}{|l|}{ Extrahepatic Metastases } \\
\hline No & $206(96.7 \%)$ & $156(96.9 \%)$ & $50(96.2 \%)$ & \multirow[t]{2}{*}{0.678} \\
\hline Yes & $7(3.3 \%)$ & $5(3.1 \%)$ & $2(3.8 \%)$ & \\
\hline
\end{tabular}

\section{Propensity score matching for younger and elderly patients}

The distributions of the risk factors and demographic characteristics differ between the younger and elderly groups. To reduce confounding and to reflect the true effect of age, a propensity score matching model was built based on the analysis of the risk factors above. Considering OS and DFS, seven variates contributed to the model: gender, CEA, and $\mathrm{\gamma}$-GT, MVI, lymphoid metastases and extrahepatic metastases. Therefore, 46 pairs of elderly patients and younger patients were finally matched. The comparisons between the two groups are shown in Table 3. 
Table 2. Prognostic Analysis of Overall Survival and Disease-free Survival Before Propensity Score Matching

\begin{tabular}{|c|c|c|c|c|c|c|c|c|}
\hline \multirow[b]{3}{*}{ Variables } & \multicolumn{4}{|l|}{ Overall survival } & \multicolumn{4}{|l|}{ Disease-free survival } \\
\hline & \multicolumn{2}{|l|}{ Univariate } & \multicolumn{2}{|l|}{ Multivariate } & \multicolumn{2}{|l|}{ Univariate } & \multicolumn{2}{|l|}{ Multivariate } \\
\hline & HR (95\%CI) & $\mathbf{P}$ & HR $(95 \% \mathrm{CI})$ & $\mathbf{P}$ & HR $(95 \% \mathrm{CI})$ & $\mathbf{P}$ & HR (95\%CI) & $\mathbf{P}$ \\
\hline Age (yrs.): $>60$ vs $\leq 60$ & $1.326(0.869-2.023)$ & 0.190 & & & $1.306(0.795-2.145)$ & 0.292 & & \\
\hline Gender: Male vs Female & $1.507(0.955-2.378)$ & 0.078 & $\begin{array}{l}1.501 \\
(0.917-2.456)\end{array}$ & 0.106 & $1.928(1.101-3.375)$ & 0.022 & $\begin{array}{l}2.453 \\
(1.339-4.495)\end{array}$ & 0.004 \\
\hline Child-Pugh Class: B vs A & $1.942(0.940-4.015)$ & 0.073 & $\begin{array}{l}1.523 \\
(0.691-3.357)\end{array}$ & 0.296 & $0.846(0.267-2.688)$ & 0.777 & & \\
\hline Comorbid illness: Yes vs No & $1.336(0.921-1.937)$ & 0.127 & & & $1.083(0.706-1.661)$ & 0.715 & & \\
\hline HBV: Positive vs Negative & $0.962(0.644-1.437)$ & 0.849 & & & $1.477(0.868-2.512)$ & 0.150 & & \\
\hline HCV: Positive vs Negative & $2.502(0.784-7.983)$ & 0.121 & & & $0.818(0.113-5.907)$ & 0.842 & & \\
\hline $\operatorname{AFP}(\mathrm{ng} / \mathrm{ml}):>20$ vs $\leq 20$ & $0.879(0.614-1.259)$ & 0.482 & & & $0.832(0.544-1.272)$ & 0.396 & & \\
\hline CEA $(\mathrm{ng} / \mathrm{ml}):>5$ vs $\leq 5$ & $1.597(1.050-2.428)$ & 0.029 & $\begin{array}{l}1.628 \\
(1.045-2.538)\end{array}$ & 0.031 & $0.825(0.465-1.464)$ & 0.512 & & \\
\hline CA199 (U/ml): >37 vs $\leq 37$ & $1.514(1.053-2.176)$ & 0.025 & $\begin{array}{l}1.117 \\
(0.763-1.635)\end{array}$ & 0.571 & $1.004(0.639-1.578)$ & 0.985 & & \\
\hline $\mathrm{TB}(\mu \mathrm{mol} / \mathrm{L}):>17$ vs $\leq 17$ & $0.938(0.599-1.471)$ & 0.781 & & & $1.000(0.593-1.685)$ & 1.000 & & \\
\hline $\operatorname{ALB}(\mathrm{g} / \mathrm{L}):<40$ vs $\geq 40$ & $1.318(0.909-1.911)$ & 0.145 & & & $1.213(0.771-1.909)$ & 0.405 & & \\
\hline $\operatorname{ALT}(\mathrm{U} / \mathrm{L}):>35$ vs $\leq 35$ & $1.285(0.900-1.834)$ & 0.168 & & & $1.644(1.074-2.516)$ & 0.022 & $\begin{array}{l}1.394 \\
(0.896-2.169)\end{array}$ & 0.141 \\
\hline GGT (U/L): $>40$ vs $\leq 40$ & $2.711(1.700-4.323)$ & $<0.001$ & $\begin{array}{l}2.069 \\
(1.228-3.485)\end{array}$ & 0.006 & $1.866(1.125-3.095)$ & 0.016 & $\begin{array}{l}1.367 \\
(0.801-2.332)\end{array}$ & 0.251 \\
\hline Ascites: Yes vs No & $1.410(0.809-2.458)$ & 0.226 & $\begin{array}{l}1.799 \\
(0.971-3.333)\end{array}$ & 0.062 & $0.501(0.187-1.342)$ & 0.169 & & \\
\hline Tumor Nodularity: Multiple vs Single & $1.557(1.055-2.298)$ & 0.026 & $\begin{array}{l}1.484 \\
(0.986-2.233)\end{array}$ & 0.059 & $1.224(0.758-1.976)$ & 0.408 & & \\
\hline Tumor Diameter $(\mathrm{cm}):>5$ vs $\leq 5$ & $2.424(1.665-3.530)$ & $<0.001$ & $\begin{array}{l}1.320 \\
(0.870-2.002)\end{array}$ & 0.192 & $1.429(0.929-2.196)$ & 0.104 & & \\
\hline Macroscopic VI: Yes vs No & $3.805(2.070-6.993)$ & $<0.001$ & $\begin{array}{l}3.211 \\
(1.765-5.841)\end{array}$ & $<0.001$ & $5.089(2.371-10.922)$ & $<0.001$ & $\begin{array}{l}3.602 \\
(1.647-7.879)\end{array}$ & 0.001 \\
\hline Microscopic VI: Yes vs No & $1.437(0.944-2.188)$ & 0.090 & $\begin{array}{l}1.542 \\
(0.994-2.394)\end{array}$ & 0.053 & $1.192(0.708-2.007)$ & 0.508 & & \\
\hline Lymphoid Metastases: Yes vs No & $2.822(1.699-4.686)$ & $<0.001$ & $\begin{array}{l}2.481 \\
(1.358-4.530)\end{array}$ & 0.003 & $2.454(1.342-4.486)$ & 0.004 & $\begin{array}{l}3.297 \\
(1.710-6.357)\end{array}$ & $<0.001$ \\
\hline Extrahepatic Metastases: Yes vs No & $\begin{array}{l}11.186 \\
(4.900-25.536)\end{array}$ & $<0.001$ & $\begin{array}{l}5.060 \\
(2.026-12.639)\end{array}$ & 0.001 & $2.987(0.710-12.566)$ & 0.135 & & \\
\hline
\end{tabular}

Table 3. Characteristics of Patients before and after Propensity Score Matching

\begin{tabular}{|c|c|c|c|c|c|c|}
\hline & \multicolumn{3}{|l|}{ Before Matching } & \multicolumn{3}{|l|}{ After Matching } \\
\hline & $\begin{array}{l}\text { Younger patients } \\
(n=161)\end{array}$ & $\begin{array}{l}\text { Elderly patients } \\
(n=52)\end{array}$ & $\begin{array}{l}\text { Std. Mean } \\
\text { Difference }\end{array}$ & $\begin{array}{l}\text { Younger patients } \\
(n=46)\end{array}$ & $\begin{array}{l}\text { Elderly patients } \\
(n=46)\end{array}$ & $\begin{array}{l}\text { Std. Mean } \\
\text { Difference }\end{array}$ \\
\hline Age (yrs.) & $47.6 \pm 8.6$ & $67.7 \pm 5.0$ & 2.872 & $47.0 \pm 8.2$ & $67.5 \pm 5.1$ & 3.015 \\
\hline \multicolumn{7}{|l|}{ Gender } \\
\hline Female & $38(23.6 \%)$ & $14(26.9 \%)$ & 0.076 & $8(17.4 \%)$ & $8(17.4 \%)$ & 0.000 \\
\hline Male & $123(76.4 \%)$ & $38(73.1 \%)$ & 0.076 & $38(82.6 \%)$ & $38(82.6 \%)$ & 0.000 \\
\hline \multicolumn{7}{|c|}{ CEA (ng/ml): } \\
\hline$>5$ & $132(82 \%)$ & $42(80.8 \%)$ & 0.031 & $39(84.8 \%)$ & $39(84.8 \%)$ & 0.000 \\
\hline$\leq 5$ & $29(18 \%)$ & $10(19.2 \%)$ & 0.031 & $7(15.2 \%)$ & $7(15.2 \%)$ & 0.000 \\
\hline \multicolumn{7}{|c|}{ GGT (U/L) } \\
\hline$>40$ & $50(31.1 \%)$ & $12(23.1 \%)$ & 0.180 & $11(23.9 \%)$ & $11(23.9 \%)$ & 0.000 \\
\hline$\leq 40$ & $111(68.9 \%)$ & $40(76.9 \%)$ & 0.180 & $35(76.1 \%)$ & $35(76.1 \%)$ & 0.000 \\
\hline \multicolumn{7}{|c|}{ Macroscopic VI } \\
\hline No & $151(93.8 \%)$ & $49(94.2 \%)$ & 0.019 & $44(95.7 \%)$ & $44(95.7 \%)$ & 0.000 \\
\hline Yes & $10(6.2 \%)$ & $3(5.8 \%)$ & 0.019 & $2(4.3 \%)$ & $2(4.3 \%)$ & 0.000 \\
\hline \multicolumn{7}{|c|}{ Lymphoid Metastases } \\
\hline No & $147(91.3 \%)$ & $41(78.8 \%)$ & 0.355 & $39(84.8 \%)$ & $39(84.8 \%)$ & 0.000 \\
\hline Yes & $14(8.7 \%)$ & $11(21.2 \%)$ & 0.355 & $7(15.2 \%)$ & $7(15.2 \%)$ & 0.000 \\
\hline \multicolumn{7}{|c|}{ Extrahepatic Metastases } \\
\hline No & $156(96.9 \%)$ & $50(96.2 \%)$ & 0.040 & $45(97.8 \%)$ & $45(97.8 \%)$ & 0.000 \\
\hline Yes & $5(3.1 \%)$ & $2(3.8 \%)$ & 0.040 & $1(2.2 \%)$ & $1(2.2 \%)$ & 0.000 \\
\hline
\end{tabular}

Note: Values in $n(\%)$, mean \pm standard deviation.

Std. mean difference: standardized mean difference 


\section{OS and DFS}

The median survival of the entire cohort was 25 months, and the overall cumulative survival rates at 1 , 3 and 5 years were $73.2 \%, 39.0 \%$, and $28.3 \%$, respectively. Stratified by age, the median overall survival of the elderly patients was lower than that of the younger patients (18.0 months vs 27.16 months). The cumulative survival rates of the elderly patients at 1,3 and 5 were $70.3 \%, 40.0 \%$ and $22.2 \%$, whereas in younger patients, they were $75.2 \%, 42.5 \%$ and $30.3 \%$, respectively. The OS rates were comparable between the younger and elderly patients (Figure 1A). After propensity score matching, the median OS was higher in the younger patients than in the elderly patients (24 months vs 18 months). The survival rates of 1,3 and 5 years in younger patients were $78.7 \%, 32.5 \%$ and $20.3 \%$, whereas in elderly patients they were $74.0 \%$, $31.7 \%$ and $23.8 \%$, respectively. However, the OS between the younger and elderly patients remains comparable (Figure 1B). Regarding the DFS, the median disease-free survival of the entire cohort was 32 months. The DFS was comparable between the younger and elderly patients before and after propensity score matching (Figure 1 C \& D).
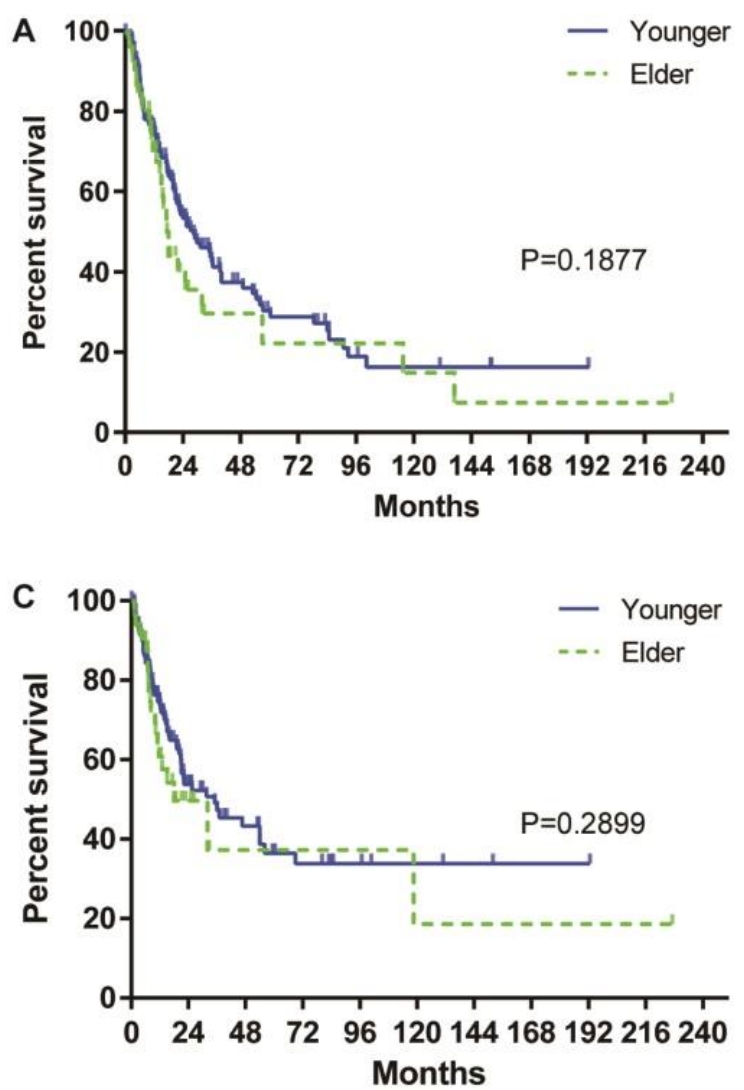

\section{Discussion}

$\mathrm{CHC}$ is a rare primary liver tumor that constitutes only $2.4 \%$ to $14.2 \%$ of all primary hepatic malignancies $[1,2,18-20]$. The $\mathrm{CHC}$ had a dual differentiation of both bile duct epithelia and hepatocytes within the same tumor ${ }^{[1,2]}$. The biological and pathological behaviors of these tumors are complex, and aggressive liver resection may provide a better prognosis ${ }^{[1]}$. The effect of age on the long-term prognosis of hepatic resection with in patients diagnosed with HCC or ICC has been extensively studied, but the results are conflicting. Propensity score matching, a new statistical method, revealed that long-term OS and DFS in elderly and younger patients with either HCC or ICC are comparable [11-15]. Although previous studies noted that $\mathrm{CHC}$ was more common in male patients older than 65 years ${ }^{[21]}$, the effect of age on the long-term prognosis of patients with $\mathrm{CHC}$ who underwent curative surgery had not been studied. Thus, a total of 269 patients who underwent hepatic resection for $\mathrm{CHC}$ at a single center was examined and analyzed OS and DFS by propensity score analysis and multivariate analysis. Due to a lack of typical imaging characteristics, preoperative diagnosis of $\mathrm{CHC}$ remains difficult. Thus, most patients with $\mathrm{CHC}$ were misdiagnosed
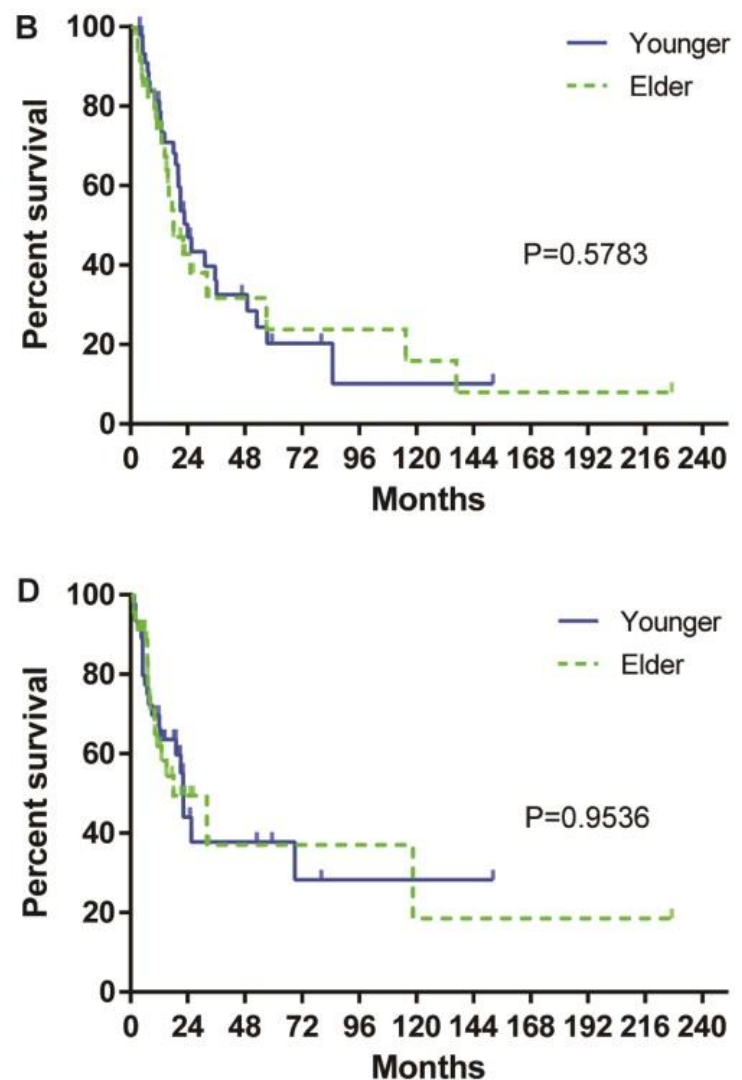

Figure 1. OS of elderly and younger patients with $\mathrm{CHC}$ before $(\mathrm{A})$ and after $(\mathrm{B})$ propensity score matching. DFS of patients with $\mathrm{CHC}$ before (C) and after (D) propensity score matching. 
either as having HCC or CC before the surgery[4, 22]. Surgical resection remains the main treatment for primary liver tumors; however, whether elderly patients may benefit from aggressive surgical treatment has not been agreed upon. Previous studies have noted that, compared to younger patients, elderly patients with HCC or ICC have a comparable OS and DFS after hepatectomy as revealed by propensity score matching [11-15]. Consistent with these studies, the OS and DFS were not significantly different between younger and elderly patients. Although elderly patients are more likely to have a worse liver function reserve and lymphoid metastases, the effect of age on the long-term prognosis was not obvious after adjusting the main confounding factors using propensity score matching or multivariate analysis. To date, the present study represents the first study to assess the effect of age on the long-term prognosis of patients who underwent resection for $\mathrm{CHC}$.

To further reveal the true effect of age on the long-term prognosis of surgical patients with $\mathrm{CHC}$, the confounding factors must be balanced between the younger and elderly patients. In the propensity score matching analysis, regardless of whether the included variates differed between the two groups before matching, the distributions of the selected variates were comparable between the matched pairs selected by the model. Thus, a multivariate analysis of the prognosis was performed in the entire cohort to identify the independent risk factors of $\mathrm{CHC}$. Consistent with previous studies ${ }^{6,21,23-26]}$, age was not identified as an independent factor in the multivariate analysis. Moreover, consistent with the multivariate analysis OS and DFS did not differ significantly between the younger and elderly patients after propensity score matching, suggesting that the younger and elderly patients with $\mathrm{CHC}$ and similar demographic characteristics and clinicopathological features had comparable long-term prognoses. Taken together, these findings suggest that hepatic resection surgery should be considered as a potential treatment in elderly patients, as elderly patients can achieve long-term survivals that are comparable to those of younger patients.

There is a clear consensus that a high prevalence of chronic HBV infection is the most common etiological factor of $\mathrm{HCC}[27]$, and $\mathrm{HBV}$ infection has been related to an increased risk of $\mathrm{CC}^{[28]} \mathrm{HBV}$ can integrate into the host genome, disrupt the expression of host genes and cause hepatocarcinogenesis even without hepatic fibrosis of cirrhosis ${ }^{[29]}$. Recently, it has been shown that HBV infection and heavy alcohol consumption may contribute to the development of $\mathrm{CHC}^{[30]}$. Consistent with the previous studies, the percentage of HBV-positive patients with $\mathrm{CHC}$ $(74.6 \%, 159 / 213)$ is much higher than normal population in our study ${ }^{[31]}$. The younger patients have a higher rate of HBV infection when compared to elderly patients $(83.9 \%$ vs $46.2 \%, \mathrm{P}<0.001)$, suggesting that $\mathrm{CHC}$ may partially share a similar mechanism with HCC--HBV infection often occurs in early childhood, and the hepatocarcinogenesis can often be observed under the influence of decades of HBV infection. However, in the subsequent study, multivariate analysis indicated that HBV infection was not an independent risk factor associated with OS or DFS. It suggesting that HBV infection was not a solid contributor to $\mathrm{CHC}$ prognosis, as $\mathrm{CHC}$ also shares the histopathologic characteristics of cholangiocarcinoma ${ }^{[23,30]}$.

Several limitations of the current study may have influenced the results. Given the nature of the retrospective study, there could be potential unmeasurable confounders between the two groups. Additionally, due to the low prevalence of this tumor, even though the research population is largest so far, the sample size is still relatively small and may affect the statistical power. In recent years, given the technical advancement of hepatectomy, the selection criteria have broadened, especially for elderly patients, which resulted in shorter follow-up times in the elderly group.

In conclusion, the long-term OS and DFS in younger and elderly patients who underwent liver resection for $\mathrm{CHC}$ are comparable. Moreover, tumor characteristics, such as MVI and extrahepatic metastases, are more powerful predictors of an unfavorable prognosis. In summary, an aggressive resection strategy could be recommended for elderly patients who have tumor characteristics that are like younger patients.

\section{Acknowledgments}

This work was supported by the grants from National Natural Science Foundation of China (No. 81773067, 81502486, 81472674); National Key Sci-Tech Project (2012ZX10002011-002); the Shanghai Committee of Science and Technology, China (No. 16JC14 04000).

\section{Financial support}

This work was supported by the grants from National Natural Science Foundation of China (No. 81773067, 81502486, 81472674); National Key Sci-Tech Project (2012ZX10002011-002); the Shanghai Committee of Science and Technology, China (No. 16JC1404 000). 


\section{Competing Interests}

The authors have declared that no competing interest exists.

\section{References}

1. Kim KH, Lee SG, Park EH, Hwang S, Ahn CS, Moon DB, et al. Surgical Treatments and Prognoses of Patients with Combined Hepatocellular Carcinoma and Cholangiocarcinoma. Ann Surg Oncol. 2009; 16: 623-9.

2. Jarnagin WR, Weber S, Tickoo SK, Koea JB, Obiekwe S, Fong Y, et al. Combined hepatocellular and cholangiocarcinoma: demographic, clinical, and prognostic factors. Ann Ny Acad Sci. 2002; 94: 2040-6.

3. DeLellis. WHO Classification of Tumours of the Digestive System, Fourth Edition. 2010.

4. Fowler KJ, Sheybani A, Rd PR, Doherty S, E MB, Chapman WC, et al. Combined hepatocellular and cholangiocarcinoma (biphenotypic) tumors: imaging features and diagnostic accuracy of contrast-enhanced CT and MRI. Ajr American Journal of Roentgenology. 2013; 201: 332-9.

5. Tang D, Nagano H, Nakamura M, Wada H, Marubashi S, Miyamoto A, et al. Clinical and pathological features of allen's type $\mathrm{C}$ classification of resected combined hepatocellular and cholangiocarcinoma: A comparative study with hepatocellular carcinoma and cholangiocellular carcinoma. J Gastrointest Surg. 2006; 10: 987.

6. Lee CH, Hsieh SY, Chang CJ, Lin YJ. Comparison of clinical characteristics of combined hepatocellular-cholangiocarcinoma and other primary liver cancers. Jastroenterol Hepatol. 2013; 28: 122-7.

7. Lee WS, Lee KW, Heo JS, Kim SJ, Choi SH, Kim YI, et al. Comparison of combined hepatocellular and cholangiocarcinoma with hepatocellular carcinoma and intrahepatic cholangiocarcinoma. Surg Today. 2006; 36: 892-7.

8. Williamson EJ, Forbes A. Introduction to propensity scores. Respirology. 2014; 19: 625-35.

9. Kim DH, Pieper CF, Ahmed A, Colónemeric CS. Use and Interpretation of Propensity Scores in Aging Research: A Guide for Clinical Researchers. J Am Geriatr Soc. 2016; 64: 2065-73

10. Garrido MM, Kelley AS, Paris J, Roza K, Meier DE, Morrison RS, et al. Methods for constructing and assessing propensity scores. Health Serv Res. 2014; 49: 1701-20.

11. Motoyama H, Kobayashi A, Yokoyama T, Shimizu A, Sakai H, Furusawa N, et al. Impact of advanced age on the short- and long-term outcomes in patients undergoing hepatectomy for hepatocellular carcinoma: a single-center analysis over a 20-year period. Am J Surg. 2015; 209: 733-41.

12. Vitale A, Spolverato G, Bagante F, Gani F, Popescu I, Marques HP, et al. A multi-institutional analysis of elderly patients undergoing a liver resection for intrahepatic cholangiocarcinoma. J Surg Oncol. 2016; 113: 420-6.

13. Miricicappa F, Gramenzi A, Santi V, Zambruni A, Di MA, Frigerio M, et al. Treatments for hepatocellular carcinoma in elderly patients are as effective as in younger patients: a 20-year multicentre experience. Gut. 2010; 59: 387-96.

14. Santambrogio R, Barabino M, Scifo G, Costa M, Giovenzana M, Opocher E. Effect of Age (over 75 Years) on Postoperative Complications and Survival in Patients Undergoing Hepatic Resection for Hepatocellular Carcinoma. J Gastrointest Surg. 2017.

15. Su CW, Lei HJ, Chau GY, Hung HH, Wu JC, Hsia CY, et al. The effect of age on the long-term prognosis of patients with hepatocellular carcinoma after resection surgery: a propensity score matching analysis. Arch Surg-Chicago. 2012; 147: 137-44.

16. Maithel SK, Jarnagin WR, Belghiti J. Hepatic resection for benign disease and for liver and biliary tumors. Elsevier Inc. 2012.

17. Pang TC, Lam VW. Surgical management of hepatocellular carcinoma. World journal of hepatology. 2015; 7: 245-52.

18. Akiba J, Nakashima O, Hattori S, Tanikawa K, Takenaka M, Nakayama M, et al. Clinicopathologic analysis of combined hepatocellular-cholangiocarcinoma according to the latest WHO classification. Am J Surg Pathol. 2013; 37: 496-505.

19. Allen RA, Lisa JR. Combined liver cell and bile duct carcinoma. Am J Pathol. 1949; 25: 647-55.

20. Goodman ZD, Ishak KG, Langloss JM, Sesterhenn IA, Rabin L. Combined hepatocellular-cholangiocarcinoma. A histologic and immunohistochemical study. Ann Ny Acad Sci. 1985; 55: 124-35.

21. Garancini M, Goffredo P, Pagni F, Romano F, Roman S, Sosa JA, et al Combined hepatocellular-cholangiocarcinoma: a population-level analysis of an uncommon primary liver tumor. Liver transplantation: official publication of the American Association for the Study of Liver Diseases and the International Liver Transplantation Society. 2014; 20: 952-9.

22. Vilchez V, Shah MB, Daily MF, Pena L, Tzeng CW, Davenport D, et al. Long-term outcome of patients undergoing liver transplantation for mixed hepatocellular carcinoma and cholangiocarcinoma: an analysis of the UNOS database. HPB (Oxford). 2016; 18: 29-34

23. Lee SD, Park SJ, Han SS, Kim SH, Kim YK, Lee SA, et al. Clinicopathological features and prognosis of combined hepatocellular carcinoma and cholangiocarcinoma after surgery. Hepatobiliary \& pancreatic diseases international: HBPD INT. 2014; 13: 594-601.
24. Yin X, Zhang BH, Qiu SJ, Ren ZG, Zhou J, Chen XH, et al. Combined hepatocellular carcinoma and cholangiocarcinoma: clinical features, treatment modalities, and prognosis. Ann Surg Oncol. 2012; 19: 2869-76.

25. Wu CH, Yong CC, Liew EH, Tsang LL, Lazo M, Hsu HW, et al. Combined Hepatocellular Carcinoma and Cholangiocarcinoma: Diagnosis and Prognosis After Resection or Transplantation. Transplant Proc. 2016; 48: 1100-4.

26. Chu KJ, Lu CD, Dong H, Fu XH, Zhang HW, Yao XP. Hepatitis B virus-related combined hepatocellular-cholangiocarcinoma: clinicopathological and prognostic analysis of 390 cases. Eur J Gastroenterol Hepatol. 2014; 26: 192-9.

27. de Lope CR, Tremosini S, Forner A, Reig M, Bruix J. Management of HCC. J Hepatol. 2012; 56: S75-S87.

28. Li M, Li J, Li P, Li H, Su T, Zhu R, et al. Hepatitis B virus infection increases the risk of cholangiocarcinoma: a meta-analysis and systematic review. Journal of Gastroenterology \& Hepatology. 2012; 27: 1561-8.

29. Guo Y, Kang W, Lei X, Li Y, Xiang A, Liu Y, et al. Hepatitis B viral core protein disrupts human host gene expression by binding to promoter regions. Bmc Genomics. 2012; 13: 563.

30. Zhou YM, Zhang XF, Wu LP, Sui CJ, Yang JM. Risk factors for combined hepatocellular-cholangiocarcinoma: a hospital-based case-control study. World J Gastroenterol. 2014; 20: 12615-20.

31. Zhang W, Ji Z, Ling W, Dan X, Yan Y. A meta-analysis of HBsAg-positive rate among general Chinese populations aged 1--59 years. Actual Pharm Biol Cl. 2015; 47: 1-11. 